\title{
Detergentes, cuñados y las revistas MDPI
}

\section{Detergents, brothers-in-law and the MDPI journals Isidro F. Aguillo}

Aguillo, Isidro F. (2021). "Detergentes, cuñados y las revistas MDPI". Anuario ThinkEPI, v. 15, e15e03.

https://doi.org/10.3145/thinkepi.2021.e15e03

Publicado en IweTel el 15 de julio de 2021

\section{Isidro F. Aguillo}

https://orcid.org/0000-0001-8927-4873

Consejo Superior de Investigaciones Científicas

Instituto de Políticas y Bienes Públicos

Laboratorio de Cibermetría

Albasanz, 26-28

28037 Madrid, España

isidro.aguillo@csic.es

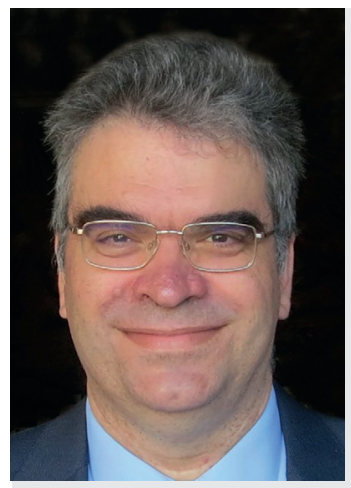

Resumen: Hay una creciente preocupación sobre el posible carácter depredador de las revistas de la editorial MDPI. El autor identifica las prácticas de dicha editorial como técnicas comerciales piramidales, que deben rechazarse en el ámbito de la comunicación científica pues afecta los criterios de selección y aceptación de originales y genera una proliferación de monográficos con cuestionables procesos de revisión. Aunque no se trata de una editorial predadora aconseja a los autores no editar o publicar con ella y a las instituciones cancelar sus acuerdos.

Palabras clave: $M D P I ;$ Revistas predadoras; Modelo piramidal; Revisión por pares. Abstract: There is growing concern about the possible predatory nature of the MDPI editorial journals. The author identifies the practices of this publisher as pyramidal commercial techniques, which should be rejected in the field of scientific communication as they affect the selection and acceptance criteria of original works and generate a proliferation of monographs with questionable review processes. Although this publisher is not predatory, it is advised that authors do not edit or publish with it and that institutions cancel their agreements.

Keywords: MDPI; Predatory journals; Pyramidal model; Peer review.

Posiblemente algunos tengáis experiencia en situaciones parecidas a esta: por alguna extraña razón acabáis en una reunión donde un vivaracho comercial os presenta una gran oportunidad de negocio. Una empresa ha lanzado una nueva línea de productos de droguería que todo el mundo debería tener. Sin entrar en muchos detalles sobre la bondad de los detergentes, empieza a explicaros cómo haceros ricos con ellos mediante un sencillo e inteligente sistema de venta. Se compra una cierta cantidad de producto (siempre hay un mínimo) para convertirse en distribuidor, lo que significa que se paga a precio de fábrica, lo que dejaría un gran margen de beneficio. Pero lo ingenioso del sistema es que no hay que venderlo bote a bote, sino convencer a terceros de que os compren todo o una parte importante del stock. Podéis ofrecerles descuentos o precios especiales y garantizarles el suministro (siempre que pidan un mínimo). Si aceptas el gran negocio ocurren dos cosas: una, llenas tu despensa (y tu cocina, tu baño, tu garaje) de docenas de coloridos envases; y dos, te conviertes tú en el vivaracho comercial, intentando convencer a todos tus conocidos de que te hagan voluminosos pedidos de un producto que ensalzas por las nubes, pero sin un conocimiento real de su bondad y de su relación precio/calidad. 
Cuando al pasar unos meses solo hayas colocado unos pocos botes a tus cuñados y estés usando ese detergente barato por siglos para quitártelo de encima, descubrirás que has sido legalmente engañado y que, como en el timo de la estampita, por listo has sido el más tonto.

Este es un modelo de negocio legal, que sigue un formato piramidal donde el esfuerzo comercial se distribuye en grupos intermedios no profesionales que, con frecuencia, se convierten en los mayores defensores y promotores de los productos. Todo ello a cambio de una pequeña parte de los beneficios que, en realidad, van a la cúpula de la pirámide, la que se lleva todo el valor añadido. Legalmente esto no es una estafa, a no ser que el producto sea manifiestamente fraudulento o que el pago se realice en negro, aunque obviamente mucho se mueve en la economía sumergida. Además, puede ser extraordinariamente exitoso pues los compradores intermedios generan un marketing agresivo prácticamente a coste cero. Pensad en los miles de pegatinas en coches con el texto "¿Quiere adelgazar?, pregúnteme cómo" de Herbalife, un ejemplo muy popular de venta piramidal.

En el mundo de las publicaciones científicas estamos en una transición de un modelo de pago por suscripciones a otro de pago por publicar, promovido por algunas de las iniciativas de acceso abierto. Al igual que con el detergente, el coste de publicar un trabajo no está claramente definido y los pre-

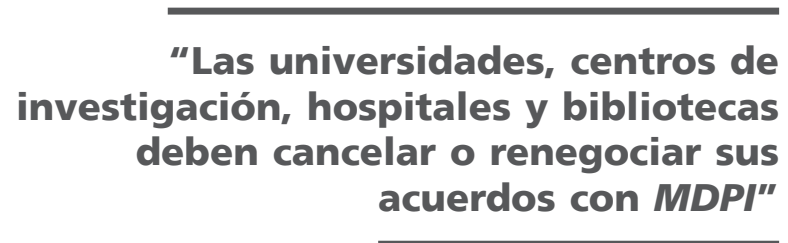
cios que las grandes editoriales intentan cobrar, los

(mal) llamados costes de procesamiento o APCs por sus siglas en inglés, son muy dispares, con casos notoriamente abusivos. Los precios se rigen con las leyes del mercado de la oferta y la demanda, donde hay un número reducido de revistas prestigiosas (con un alto factor de impacto) y un gran número de investigadores con salarios y promociones ligados a la publicación en esas revistas. A decir verdad, aunque hay grupos muy combativos en contra de estas prácticas, la gran mayoría de los investigadores senior, bien financiados con fondos públicos o de terceros, parecen haber aceptado este escenario y solo reclaman una regulación mínima (Plan S).

En este contexto surgen editoriales como MDPI, o posteriormente Frontiers, que, apoyadas en un modelo de acceso abierto, llevan a cabo un sistema claramente piramidal y que fueron clasificadas por algunos autores como revistas predadoras. La visita beligerante de un alto responsable de Frontiers a la Universidad de Colorado, tras aparecer dicha editorial en la lista Beall de revistas predadoras, tuvo como consecuencia directa la desaparición de la citada lista, lo que manifiesta la verdadera naturaleza de esas empresas. En los últimos años MDPI se ha lanzado a una exitosa campaña de captación de originales mediante un sistema piramidal más elaborado, donde, mediante invitación a editores de números monográficos, estos realizan todo el trabajo a cambio de algunas supuestas ventajas. Estos editores se convierten en comerciales a coste cero, colocan sus propios trabajos en condiciones favorables e incluso ofrecen a colegas y discípulos descuentos por su participación en dichos monográficos. Tampoco olvidemos que implícitamente se utiliza cierto chantaje de proximidad (amistad, cooperación, dependencia) para lograr esos manuscritos. Eventualmente MDPI ha firmado acuerdos con un gran número de instituciones que, a cambio de "descuentos" y otras ventajas, se convierten mediante esta colaboración en comerciales de la editorial y fuente de correos spam invitando a sus investigadores a publicar preferentemente en sus revistas.

Las revistas MDPI se han multiplicado, han escalado posiciones en los cuartiles y ahora publican ya un porcentaje muy alto del total de artículos científicos (puede verse el análisis de un caso concreto en Repiso; Merino-Arribas; Cabezas-Clavijo, 2021). El rápido crecimiento, involucrando cada vez más editores invitados, ha aumentado la diversidad profesional de los mismos y ya empiezan a aparecer retractaciones, trabajos irrelevantes y fuertes sospechas de prácticas de revisiones por pares pobres. El modelo piramidal abre la puerta a ese tipo de prácticas, especialmente cuando prioriza los intereses comerciales de la editorial y los intereses personales (carrera profesional) de los autores, no siempre bien informados o bien intencionados.

No, las revistas MDPI no son predadoras. No, la mayoría de sus artículos tienen indudable valor y no pueden ser excluidos. Pero, sí, los números monográficos con editores invitados deben desaparecer. $Y$ sí, las agencias y comités éticos deberían revisar las acciones de algunos editores invitados y autores. Y sí, las universidades, centros de investigación, hospitales y bibliotecas deben cancelar o renegociar sus acuerdos con MDPI.

\section{Referencia}

Repiso, Rafael; Merino-Arribas, Adoración; Cabezas-Clavijo, Álvaro (2021). “El año que nos volvimos insostenibles: Análisis de la producción española en Sustainability (2020)". Profesional de la Información, v. 30, n. 4, e300409.

https://doi.org/10.3145/epi.2021.jul.09 